\title{
Should We Teach English Early? \\ (Some Considerations)
}

\section{Patuan Raja}

Universitas Lampung, Bandar Lampung

\begin{abstract}
English has been introduced in early levels of elementary schools apparently based on the assumption the earlier the better. The present article reviews some literature on the relation between age and second language acqusition and has to conclude that the assumption does not have solid foundation. It also discusses the implications relevant to Indonesian context, especially concerning amount of instructional time, educational value, and resources.
\end{abstract}

Keywords: Second language learning, critical period, cognitive academic language profiliency, instructional time, decentralization.

English has been introduced in early levels of elementary schools apparently based on the assumption the earlier the better. The present article reviews some literature on the relation between age and second language acquisition and has to conclude that the assumption does not have solid foundation. It also discusses the implications relevant to Indonesian context, especially concerning amount of instructional time, educational value, and resources.

In the previous decades, the teaching of English as a foreign language in Indonesia had always started in the first year of junior high school. In the present decade, however, this has changed. Nation-wide, English has been formally allowed to be introduced in elementary school. Some schools start this foreign language instruction in the fourth grade, some others in the first grade. Lately, even kindergarten and play-group children have been provided with an English lesson of some sort.

It should be admitted that this phenomenon is interesting since it leads to a very crucial question: what institution is to be held responsible for producing the needed teachers of English of such young learners? The English departments of IKIP's and FKIP's are designed to supply English teachers to senior-not even junior-high schools. The question is crucial 
considering the fact that pre-school children, young school children, older child learners, adolescents, and adults differ psychologically in their approach to second language learning ${ }^{2}$ (Stern, 1983), meaning that younger children should be treated differently from older learners not only in the process of teaching but also in the process of achievement assessment. This will be taken up again later. For the time being, however, although crucial, the question has not yet become very urgent since the provision of English lesson in elementary school is mainly implemented in big cities and has not so far been declared as a national educational policy to be implemented throughout the country.

Nevertheless, the phenomenon reflects an underlying assumption that, if English is introduced at an earlier age, a better proficiency level might be attained. Apparently, the attempt to start providing English instruction to younger children seems to be undertaken as a possible solution to the problem of senior high school graduates' low achievement level, a problem widely acknowledged (Yusuf and Sewoyo, 1997). Thus, in the context of the teaching of English as a foreign language in Indonesia, a firm opinion concerning the age factor evidently begins to take form. Such a stance, once taken, would be hard to reverse, particularly if it has been translated into national and or local language education policies and practices.

As one of learner characteristics, age has often been thought of as a major factor determining success in learning a second or foreign language. Figure 1 shows how language learning process, which is affected by both learner characteristics and learning conditions, determines the quality of the learning outcomes. Stern (1983) lists three other factors in addition to age-cognitive, affective, and personality characteristics.

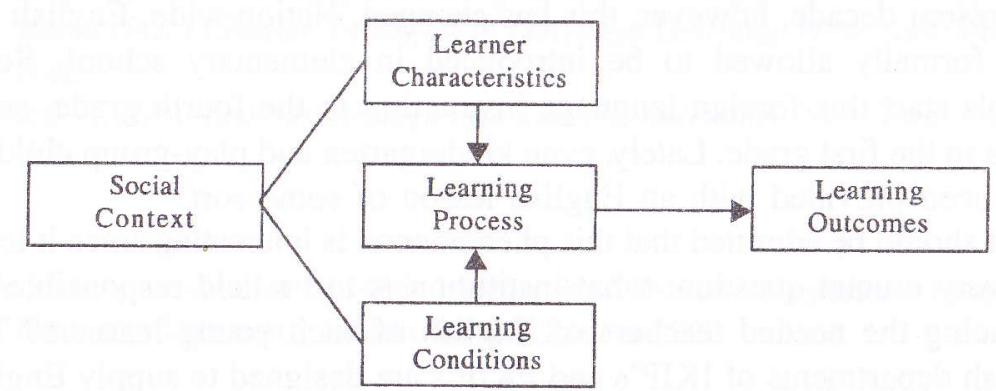

Figure 1 Stern's (1983) second language learning model

${ }^{2}$ In this paper, there is no specific distinction made between acquisition and learning
In fact, the age factor in relation to second language teaching and learning has been one of the most debated issues (Stern, 1983). He adds that "Even after more than thirty years of serious discussion and some research on this question, the issue of the relationship between age and second language learning has been far from resolved." Somehow, this 17 -year-old observation is still relevant today, meaning that the age factor in language learning remains a tentative hypothesis. Lightbown and Spada (1994) agree to this, stating that the role of age in second language acquisition is still a much debated topic.

Therefore, the present paper is intended to critically review some literature concerning the relation between age and second language (L2) ${ }^{3}$ acquisition-together with the educational implication-since this may entail fundamental as well as far-reaching consequences in the policies and practices of the teaching of English as a foreign language in Indonesia, especially in the present and future era of educational decentralization, when decisions regarding educational policies would largely be in the hands of the local government agencies.

\section{THE CRTTCAL PERIOD HYPOTHESIS (CPH)}

The relation between age and language acquisition is embodied in a hypothesis called the critical period hypothesis $(\mathrm{CPH})$, which was originally conceived by Penfield and Roberts in 1959 and later refined by Lenneberg in 1967 to account for the difficulty of acquiring first language (L1) after puberty.

$\mathrm{CPH}$ has its roots in the studies on imprinting and other instinctive behaviors in several species of birds and fish (Long, 1990; Clark and Clark, 1977). Imprinting is the formation of attachment between an organism and an object in its immediate environment, and is found to occur only during a very brief period of time after hatching, after which imprinting is thought to be difficult, if not impossible (Hergenhahn, 1982). For example, a newly hatched duckling would form an attachment to any kind of moving object and follow it as its mother provided that the object is presented at just the right moment in its life. If attachment formation does not occur during this critical period, it may never take place.

${ }^{3}$ The term "L2" covers both second and foreign languages. When specific reference is being made to foreign language learning, some emphasis will be made. 
$\mathrm{CPH}$ states that there is a period, which approximately falls within the first ten years of life, when language acquisition takes place naturally and effortlessly due to the plasticity of the brain. With the onset of puberty, this plasticity begins to disappear as the result of the lateralization of the language function in the left hemisphere of the brain (Ioup et al, 1994; McLaughlin, 1984; Ellis, 1986). That is, the neurological capacity for understanding and producing language, which initially involves both hemispheres of the brain in very young children, is slowly concentrated in the left hemisphere. This lateralization process is thought to complete by puberty, marking the end of the critical period (Clark and Clark, 1977).

There seem to be two problems with the $C P H$ in relation to $L 1$ acquisition. First, there is no overall agreement among neurologists and psycholinguists as to the definite end of the brain plasticity. The CPH predicts that $\mathrm{L} 1$ acquisition is not possible if a child is not exposed to the language before the end of the critical period, which is, however, defined differently by different people. For example, the end is thought to occur at age 9 (McLaughlin, 1984), between 9-12 (Ioup et al, 1994), at 13 (Long, 1990), and at 15 years of age (Patkowski, 1980, and Johnson and Newport, 1989). These differing opinions conceming the completion of the period seem to result from the difficulty to precisely, and neurobiologically, determine the end of the lateralization process. Clark and Clark (1977) state that "Many investigators have argued that lateralization occurs long before puberty and may be complete by age two." Furthermore, Lenneberg is reported to set lateralization perfection at puberty, Krashen at age 5 , and some other people at 0 , meaning that at or even before birth the lateralization is considered to have already terminated (Dulay et al, 1982).

Secondly, Clark and Clark (1977) assert that "Whether or not there is really a critical period hasn't been established with any certainty yet." In other words, they are saying that the effect of neurobiological processes in the human brain on the acquisition of an L1 has not been proven with clarity as yet. In the same vein, Dulay et al (1982) contend that "The association of cerebral dominance with language acquisition ability has never been substantiated." Similarly, McLaughlin (1984) holds that "The critical period hypothesis remains very much a hypothesis."

\section{CPH AND L2 ACQUISITION}

It has been attempted in the previous section to show how the $\mathrm{CPH}$ has met some resistance when related to $\mathrm{L} 1$ acquisition. The same thing can be said to happen when the hypothesis is related to the acquisition of an L2. In L2 acquisition, the CPH is found in two versions: the strong and the weak (Long, 1990). The strong version, that acquiring an L2 can occur only within the critical period, is widely rejected. The weak version, also known as the sensitive period hypothesis, states that some L2 learning is possible after a certain age but that native-like ability is unattainable (Long, 1990).

In the context of L2 acquisition, it is the weak version of the CPH that is said to have been long debated (Stern, 1983). Patkowski (1980) rejects the strong but advocates the weak version when asserting that " $I t$ is indeed possible to acquire a second language after the sensitive period, but it would be theoretically not possible to do so to the extent of attaining native-like proficiency..." On the other hand, Dulay et al (1982) maintain that, even if some agreement as to the definite end of brain lateralization can be achieved, "The demonstration that lateralization is complete by a certain age does not establish that learners younger than that age can acquire an L2 perfectly while learners older than that age cannot." In other words, they reject the weak version as well.

The debate continues. Long (1990), in an extensive review of research on the relation between age and L2 proficiency, claims that there are sensitive periods governing second language development. He then offers a challenge by expressing that "The easiest way to falsify the sensitive period hypothesis] would be to produce learners who have demonstrably attained native-like proficiency despite having begun exposure well after the closure..." As a response to this challenge, Birdsong (1992) reports his study which he claims has offered convergent experimental evidence which suggests there are exceptions to this generalization [that native-like competence cannot be achieved by postpubertal learners]. With a similar purpose, and with a more natural approach, Ioup et al (1994) report their finding of an adult who had never had formal instruction in Egyptian Arabic, who immigrated to Cairo at the age of 21, who had lived in Egypt for 26 years, and who showed 
a phenomenal success in acquiring native proficiency in the language in an untutored setting.

In the mean time, Lightbown and Spada (1994) list several points based on which the association between $\mathrm{CPH}$ and $\mathrm{L} 2$ acquisition can be questioned: (1) learning in similar circumstances, older learners have been shown, at least in the early stages, to be more efficient than younger learners (see, for example, Krashen et al, 1979); (2) learners who begin learning an L2 at the primary school do not fare better in the long run than learners who begin in early adolescent, that is, at the secondary school (see, for example, Carroll, 1975; and Ramirez and Politzer, 1978); and (3) there are a number of accounts about older learners (adolescents and adults) who have reached high levels of proficiency in an L2 (see, for example, Stevick, 1989; Birdsong, 1992; and Ioup et al, 1994).

It should be admitted that, while $\mathrm{L} 1$ acquisition is homogeneous in the sense that eventually all normal children acquiring their $\mathrm{L} 1$ reach native proficiency, adult L2 acquisition is much more heterogeneous, meaning that some adult leamers are highly successful, some only moderately, and some others not at all whereas most children are more successful in L2 acquisition (Patkowski, 1980, and Birdsong, 1992). Unluckily, it so happens that this variability in L2 attainment comes to be interpreted as directly attributed to age. However, although older learners are admittedly less likely than younger learners to master an L2, a close examination of studies relating age to $L 2$ acquisition reveals that age differences reflect differences in the situation of learning rather than in capacity to learn (Marinova-Todd et al, 2000).

Having scrutinized more than 35 studies dealing with the relation between age and L2 acquisition, Marinova-Todd et al (2000) show that the researchers have committed three common mistakes: misinterpretation, misattribution, and misemphasis. Many researchers have mistakenly interpreted children L2 ultimate achievement as a proof that children learn quickly and easily. Marinova-Todd et al assert that, although children are more likely to reach native-like proficiency in an L2, it does not necessarily mean that they learn more quickly and more easily. Some other factors may be more responsible for this attainment than the age factor. Some studies have shown that older learners in an L2 environment are generally faster and more efficient in the initial stages.

As evidence, Marinova-Todd et al quote a study which concludes that, at early stages of phonological acquisition, adolescents perform better than children. Also quoted is another study carried out in Canada with a finding that English speakers receiving late immersion French programs ( $\mathrm{L} 2$ introduced in Grade 7 or 8 ) perform as well as or better than children in early immersion programs (L2 introduced in kindergarten or Grade 1). In addition, Ramirez and Politzer (1978) believe that their study, involving subjects in kindergarten, grades 1, 3, 5, and high school, "...shows both superiority as well as possible advantage of the high school age L2 learner compared with the kindergarten beginner."

Researchers investigating the relationship between age and L2 acquisition have turned to neuroscience for more conclusive evidence. However, Marinova-Todd et al (2000) assert, neuroscientists have often committed an error of misattribution, assuming that differences in the location of two languages in the brain or in speed of processing account for differences in proficiency levels and explain the poorer performance of older learners. For example, in a recent, widely reported study, it was found that late bilinguals had two distinct but adjacent centers of activation in Broca's area corresponding to their L1 and L2, whereas in the brains of early bilinguals there was no separation of the areas of activation associated with the two languages. Another series of neurobiological studies showed differences between younger and older L2 leamers in activation patterns and in location of language processing. What these studies failed to demonstrate, Marinova-Todd et al claim, is how the differentiation of $\mathrm{L} 1$ and $\mathrm{L} 2$ brain activation patterns and processing localization is related to differences in L2 proficiency. That is, neither different activation patterns nor different language processing in young and older L2 learners have been shown to relate to different proficiency levels.

To back up their observation, Marinova-Todd et al (2000) quote a study which examined the relation between degree of lateralization of the two languages in bilinguals' brains and their L2 proficiency. The study concluded that the different localization of L1 and L2 cannot account for poorer knowledge of one of the languages. They also discuss another study which compared subjects who were first exposed to their L2 before age 6 with those exposed to it after that age. The study revealed that any difference in proficiency in an $L 1$ or $L 2$ cannot be attributed to the different localization of the two languages in a bilingual brain. 
The third, and the most common, error is that of placing an enormous emphasis on unsuccessful adult L2 learners and ignoring the older learners who achieve native-like L2 proficiency (but see also Birdsong, 1992, and Ioup et al, 1994). Marinova-Todd et al (2000) attribute this misemphasis to averaging and testing. Many studies, both for and against the $\mathrm{CPH}$, have shown that whereas younger learners tend to perform fairly similarly to one another, older learners show great variation in their proficiency. In spite of this, most researchers, they say, have provided only average scores for each age group and paid little or no attention to the adults who performed at the native or near-native level. One study, for example, concluded that older learners are less proficient than younger learners, yet a few adolescent and adult learners involved in the study actually outperformed some of the younger learners both in speed of language processing and in the number of correct responses in the L2.

In testing procedures, considering the difficulty in collecting spontaneous pronunciation data from younger children, some studies have relied on reading-aloud and imitation tasks. On the other hand, Marinova-Todd et al (2000) point out, older leamers show better pronunciation performance through spontaneously elicited speech than through reading-aloud and imitation tasks. This is due to the fact that adult L2 leamers pronunciation of spontaneous speech may have been flawless since they are familiar with the expressions of their own choice. Similar testing problem can be found in studies involving grammaticality judgment tasks presented orally which showed younger learners' better performance. In fact, both older L2 leamers and adult native speakers responded faster and better to written stimuli, revealing that poor older learners' performance on orally presented tasks reflect poorer quality of general auditory processing and attention, rather than inferior linguistic capabilities. Johnson's (1992) comment is relevant to and somehow justifies the existence of this problem in testing adult L2 learners: "...adult learners" performance is more easily influenced by the performance characteristics of the tests used to measure competence than is the younger learners' performance."

Having demonstrated the three common mistakes often committed by many researchers investigating the relation between age and L2 acquisition, Marinova-Todd et al (2000) conclude that "Age does influence language learning, but primarily because it [age] is associated with social, psychological, educational, and other factors that can affect
L2 proficiency, not because of any critical period that limits the possibility of language learning by adults." In other words, younger L2 learners are more likely to achieve native-like L2 mastery than older learners. However, this should not be interpreted to mean that adults have more problems in L2 learning because they are adults, that is, because they are past the critical period. As shown previously, age as a neurobiological construct does not seem to directly affect L2 acquisition. Age is a determinant factor of L2 proficiency only since it is interrelated with other variables.

In addition to age, Stern (1983) lists three other factors that may influence L2 learning process and outcomes-cognitive, affective, and personality characteristics. Lightbown and Spada (1994) discuss two agerelated factors that make younger learners may achieve native-like mastery: language learning environment and affective variable. In addition to neurological factor, Larsen-Freeman and Long (1991) offer three other causes of age-related L2 proficiency variability: social-psychological, cognitive, and input. Similarly, Long (1990), admitting that a sensitive period hypothesis does not explain the phenomena to which it is applied, forwards three factors, besides neurological, neurophysical factors: (a) social, psychological, affective factors, (b) input factors, and (c) cognitive factors. Thus, it is reasonable to suspect that it is these other factors, instead of age, that directly bring about the differences in ultimate L2 attainment between younger and adult learners

\section{MPLICATIONS}

Up to this point, the term "L2" covers both second and foreign languages. In this section, however, more interest will be placed on the acquisition of a foreign language since it is more relevant to the status of English in Indonesia. The most significant difference between second and foreign languages, it should be reminded, is that a second language is not a native language but is used quite widely as a medium of communication (e.g., in education and government), whereas a foreign language is a language taught as a school subject and thus is not used as a medium of instruction in schools nor as a medium of wider communication (Richards et al, 1992).

The intense debate over the effect of the age factor on the acquisition of a second/foreign language is central since it leads to the 
optimal age for starting a foreign language program within the formal education system. Those subscribing the CPH would obviously vote for the earliest possible introduction, meaning in kindergarten or in early grades of elementary school, while those rejecting the CPH would certainly promote a foreign language program to be introduced in high school. Since the exact role of age in the attainment of a second/foreign language is far from convincing, utmost care should be taken in considering the feasibility and even the desirability of starting a foreign language program in kindergarten or early elementary school.

Believing that language learning may occur at different maturity levels from the early years into adult life and that no age or stage stands out as optimal or critical for all aspects of second/foreign language learning, Stern (1983) proposes three criteria that should govern the decision at what stage in the schooling system a foreign language should be started: (1) the estimated time necessary to reach a desired level of language proficiency by a specified stage in the school of the majority of learners; (2) the educational value attributed to learning a foreign language at a given stage of the curriculum; and (3) the human and material resources required to develop and maintain an educationally sound and successful foreign language program.

\section{TME}

The first criterion proposed is consideration about the amount of time needed to achieve the desired level of proficiency. Implied in this criterion is a prerequisite need for a clearly stated goal of instruction. This is supported by Lightbown and Spada (1994) who stress that "The decision about when to introduce second language program must depend on the objectives of the language program in the particular social context..." They add that "When the objective is native-like or near native-like performance in the second language, then it is desirable to begin exposure to the language as early as possible." Although the 1994 high school English curricula are based on the so called communicative and meaningfulness approaches, the primary goal of the English instruction is still the development of reading skill (Sadtono, 1987, Depdikbud, 1987, 1992, Huda, 1994). The teaching of English in the university is also intended primarily to promote the development of reading skill (Coleman et al, 1997).
Cummins (quoted, among others, in Stern, 1983, Ellis, 1986, and Larsen-Freeman and Long, 1991) distinguishes two kinds of language proficiency: basic interpersonal and communicative skills (BICS) and cognitive academic language proficiency (CALP). In the context of second language teaching, it might be desirable to set both types of language ability as the ultimate goal of instruction. For the minority Vietnamese children living in Australia, for example, it is advantageous to have both BICS and CALP since they are expected not only to be able to carry out day-to-day communication effectively in English as their second language but also to be able to take maximum benefit from the Australian education system, in which English is the medium of instruction.

On the other hand, in the context of foreign language teaching, as in the context of the teaching of English in Indonesia, CALP should be conceived to far outweigh BICS as ultimate goal candidate. In other words, Indonesian students should be provided with a language program designed to develop CALP rather than BICS. One reason is that, as Sadtono (1987) rhetorically poses, it should be questioned on what occasions our students will use English orally outside the classroom for genuine communication and with what frequency. Considering the status of English as a foreign language in Indonesia and judging from a national level, instead of a number of cases in several big cities and centers of tourism, it is no wonder that his reply is that "They practically never use it." Similar opinion is expressed by Abbott (1987) who states that "...school-children may have no use for English outside the EFL lesson." In other words, nation-wide, it can be assumed that the majority of our students would not find themselves in situations requiring BICS. Thus, it is not BICS that our students need to be provided with. Secondly, considering the aim of English teaching in our schools, especially in university, which is to promote reading skill so that students will be capable of reading scientific journals (Kartasasmita, 1997, Yusuf and Sewoyo, 1997, and Supriyanto, 1997), it is clearly CALP that our students need to develop.

Collier (1987), concluding a study involving 1,548 language minority subjects aged 5-15 with 75 different L1's and with data cross-sectionally collected for 10 years, reports that "...at least 4-8 years nay be required for all ages of LEP [limited English proficient] students to reach national grade-level norms of native speakers in all subject 
areas of language and academic achievement..." That is, for those students to achieve native-like level of CALP in a second language setting takes between 4 and 8 years. In a foreign language context, where exposure to the target language in general can only be provided within the four walls of the classroom, the figures will be greater if native-like mastery is to be aimed at.

However, the goal of an instructional program in foreign language, such as English in Indonesia, is not to achieve native-like mastery. This modest goal is related to fact that in Indonesia English is not used as a medium of instruction in elementary or high school, whereas Collier's (1987) subjects were immersed in the main stream educational system where English is the medium of instruction. This reasonable goal is also somehow justified since Lightbown and Spada (1994) opine that "One or two hours a week-even for seven or eight years-will not produce very advanced second language speakers." As stated previously, the main objective of English teaching in Indonesia is the development of reading skill to the level that students are able to obtain information they might need from scientific and academic printed materials. Thus, 4 to 8 years may still be applicable to reflect the amount of time needed for Indonesian students to achieve the working level of CALP in English.

More relevantly, Carroll (1975) implemented a project with considerable size and complexity evaluating the educational achievement of the teaching of French as a foreign language in eight countries. A battery of language proficiency assessment was administered, covering listening, reading, speaking, and writing skills. He came to the conclusion that "...about 7.3 years of study would be required to permit students, on the average, to attain this maximum score [on readingl." However, for one sample in the US, the instructional time needed to attain the same score is 4.4 years; for another sample also in the US, it is only 1.8 years. Other factors determining the proficiency level attainment besides the amount of instructional time, he found, are verbal ability, motivation, aptitude, teaching method, and teachers' skill.

Thus, it is quite reasonable to assume that the amount of instructional time needed by our students to achieve a moderate level of reading proficiency in academic cognitive English would be about 6 to 8 years. With student selection-meaning that English is offered as an electiveand with more qualified teachers, the time might be much reduced.

\section{EDUCATIONAL VALUE}

Stern's (1983) second criterion that should govern the decision about the start a foreign language program in the schooling system is the educational value attributed to learning the foreign language at a given stage of the curriculum. It must be admitted that, except in the tertiary level where students are expected to be able to obtain information from journals and other printed materials in English, there seems to be no educational value of being able to read in English-nor of possessing other English skills at that. Compared to the context of second language learning, such as the immersion program reported by Collier (1987), where the students' success or failure at school depends to a large extent, if not totally, on the level of the target language proficiency they managed to achieve, by no means does our students' achievement in school subjects-except in the English subject-depend on how well they master English.

In addition to lending little educational value, the early introduction of a foreign language program into the schooling system may at times be educationally disadvantageous instead. Lightbown and Spada (1994) warn us that "...in the case of children from minority language backgrounds or homes where language, literacy, and education are not well-developed, an early emphasis on the second language (the language of the majority) may lead to academic and personal problems...[and] may entail the loss or incomplete development of the child's first language." McLaughlin (1984) agrees to this when he observes that "...there must be a minimal proficiency in the first language, especially in linguistic minority children whose first language is threatened by the acquisition of a second language." In Indonesia, this observation is perhaps more relevant to the teaching of Indonesian than to that of English. Still, it may hold true also for the early introduction of English as a foreign language in our schooling system, meaning that, if care is not taken, such an untimelly introduction may induce a calamity. Stern (1983) relates of a UNESCO report communicating how a premature start in a foreign language in certain educational systems has led to a vigorous demand for early education in the mother tongue. Therefore, Lightbown and Spada (1994) comment that "When...there is a strong commitment to maintaining and developing 
the child's native language, it may be more efficient to begin second language teaching later."

\section{RESOURCES}

In addition to considerations about the span of time needed to reach the learning goal and about the educational value of the target language mastery, in examining the appropriate time to start a foreign language program in the schooling system, Stern (1983) also forwards the criterion of the human and material resources required to develop and maintain an educationally sound and successful program. First of all, this means that, should it be nationally or locally programmed to introduce English in kindergarten or early elementary school grades, the constant supply of teachers qualified for teaching a foreign language to very young children should be considerably secured. This might call for the existence of a separate department at IKIP's and FKIP's, which in turn will require an accountable faculty staff. At present, however, very few lecturers of IKIP and FKIP specialize in the teaching of a (foreign) language to young children. Secondly, the demand for material resources, such as learning facilities, textbooks, teaching aids, and procedures of assessment, which are specifically made to attune to young children's stage of psychological development, should also be deliberately prepared. These efforts to provide qualified teachers and unique material resources should be maintained if the program is to succeed.

Summarizing the implication, in the present era of decentralization, local governments will face greater responsibility in the making of educational policies. With school-based management, it will even be possible for a particular school to adapt the national curriculum to meet specific local needs (Kompas, 2000). Should a certain school or a certain educational district office consider introducing English at an early level, it should first of all make sure that it has realistically checked that the instructional goal to be accomplished is justifiably achievable, that it has carefully calculated the logical amount of time needed to achieve the goal, that it has thoroughly assessed the advantages-as well as the potential disadvantages-of the language program with regard to the students' more immediate needs for achievement in other school subjects, and that it has in actuality secured the necessary human and material resources for excellent running of the language program, i.e., it has convincingly shown that it can ensure the provision of the needed well-qualified English teachers specifically trained for handling young learners as well as the required textbooks and other teaching facilities so designed to suit young learners. Otherwise, Cross (1987) expresses "I argue here that in countries where conditions such as I have described exist, there should be a narrowing down of EFL provision."

\section{CLOSING}

In the present paper, some literature concerning the relation between the age factor and the success or failure in acquiring an L2 has been closely reviewed. At the present state of investigation into this issue, age cannot be said with a certainty to have been established to directly lend considerable effect on L2 mastery. Thus, the opinion that a foreign language program should be started as early as possible within the schooling system might at best be considered as standing on shaky grounds. More importantly, the decision as to when to introduce such a program should only be made after careful contemplation of least three criteria - the time needed to achieve the intended level of foreign language proficiency, the educational value of the language program, and the availability and maintenance of the human and material resources.

\section{REFERENCES}

Abbott, G. 1987. EFL as Education. System, Vol. 15, No 1.

Birdsong, D. 1992. Ultimate Attainment in Second Language Acquisition. Language, Vol. 68, No 4, pp.706-755.

Carroll, J. B. 1975. The Teaching of French as a Foreign Language in Eight Couniries. New York: John Wiley and Sons.

Clark, H. C. and Clark, E. V. 1977. Psychology and Language: An Introduction to Psycholinguistics. San Diego: Harcourt Brace Jovanovich.

Coleman, H., Soedradjat, T. M., and Westaway, G. (Eds.) 1997. Teaching English to University Undergraduates in the Indonesian Context: Issues and Developments. Bandung: ITB Press.

Collier, V. P. 1987. Age and Rate of Acquisition of Second Language for Academic Purposes. TESOL Quarterly, Vol. 21, No 4, pp.617-641.

Cross, D. 1987. A Language Policy for EFL? System, Vol. 15, No 1. 
Depdikbud. 1992. Garis-Garis Besar Program Pengajaran Mata Pelajaran Bahasa Inggeris Sekolah Menengah Umum. Jakarta: Depdikbud.

Depdikbud. 1987. Garis-Garis Besar Program Pengajaran Bidang Studi Bahasa Inggeris. Jakarta: Depdikbud.

Dulay, H., Burt, M., and Krashen, S. 1982. Language Two. Oxford: Oxford University Press.

Ellis, R. 1986. Understanding Second Language Acquisition. Oxford: Oxford University Press.

Hergenhahn, B. R. 1982. An Introduction to Theories of Learning. Englewood Cliffs, NJ: Prentice Hall.

Huda, N. 1994. Principles of Meaningful Approach in the 1994 English Curriculum. Paper presented at the $42^{\text {nd }}$ TEFLIN Seminar, Ujung Pandang.

Ioup, G., Boustagui, E., Tigi, M. E., and Moselle, M. 1994. Reexamining the Critical Period Hypothesis. Studies in Second Language Acquisition, Vol. 16, pp. 73-98.

Johnson, J. and Newport, E. 1989. Critical Period Effects in Second Language learning. Cognitive Psychology, Vol. 21, pp.60-99.

Johnson, J. S. 1992. Critical Period Effects in Second Language Acquisition: The Effect of Written versus Auditory Materials on the Assessment of Grammatical Competence. Language Learning, Vol. 42, No 2, pp.217-248.

Kartasasmita, B. G. 1997. Teaching English to ITB Undergraduates: Observations and Suggestions. In Coleman, H., Soedradjat, T. M., and Westaway, G. (Eds.), Teaching English to University Undergraduates in the Indonesian Context: Issues and Developments. Bandung: ITB Press.

Kompas. November 22, 2000. Kabupaten dan Kota Dapat Memodifikasi Kurikulum Baru, p.9.

Krashen, S. D., Long, M. H., and Scarcella, R. C. 1979. Age, Rate, and Eventual Attainment in Second Language Acquisition. TESOL Quarterly, Vol. 13, No 4, pp.573-582.

Larsen-Freeman, D. and Long, M. H. 1991. An Introduction to Second Language Acquisition Research. London: Longman.

Lightbown, P. and Spada, N. 1994. How Languages are Learned. Oxford: Oxford University Press.

Long, M. H. 1990. Maturational Constraints on Language Development. Studies in Second Language Acquisition, Vol. 12, pp.251-285.

Marinova-Todd, S. H., Marshall, D. B., and Snow, C. E. 2000. Three Misconceptions About Age and L2 Learning. TESOL Quarterly, Vol. 34, No 1, pp.934.

McLaughlin, B. 1984. Second Language Acquisition in Childhood: Volume 1. Preschool Children (2nd Ed.). Hillsdale, NJ: Lawrence Erlbaum.
Patkowski, M. S. 1980. The Sensitive Period for the Acquisition of Syntax in a Second Language. Language Learning, Vol. 30, No 2, pp.449-472.

Ramirez, A. G. and Politzer, R. L. 1978. Comprehension and Production in English as a Second Language by Elementary School Children and Adolescents. In Hatch, E. M. (Ed.), Second Language Acquisition: A Book of Reading. Rowley, Massachusetts: Newbury House.

Richards, J. C., Platt, J., and Platt, H. 1992. Longman Dictionary of Language Teaching and Applied Linguistics. Harlow, Essex: Longman.

Sadtono, E. 1987. Pendekatan Komunikatif (Communicative Approach). In Sadtono, E. (Ed.), Antologi Pengajaran Bahasa Asing. Jakarta: Depdikbud.

Stern, H. H. 1983. Fundamental Concepts of Language Teaching. Oxford: Oxford University Press.

Stevick, E. W. 1989. Success with Foreign Languages: Seven Who Achieved It and What Worked for Them. New York: Prentice Hall.

Supriyanto, B. 1997. Teaching and Learning Reading at ITB. In Coleman, H., Soedradjat, T. M., and Westaway, G. (Eds.), Teaching English to University Undergraduates in the Indonesian Context: Issues and Developments. Bandung: ITB Press.

Yusuf, M. and Sewoyo, S. 1997. The Evaluation of ELT at Trisakti University and Its Follow-Up. In Coleman, H., Soedradjat, T. M., and Westaway, G. (Eds.), Teaching English to University Undergraduates in the Indonesian Context: Issues and Developments. Bandung: ITB Press. 